\title{
De las "metáforas culturales"a la "metonimia discursiva" en la crítica latinoamericana. Alrededor del contrapunto entre "hibridez" de Néstor García Canclini y "sujeto migrante" de Antonio Cornejo Polar
}

\author{
From "cultural metaphors" to "discursive metonymy" in Latin \\ American criticism. Around the counterpoint between "hybridity" by \\ Nestor Garcia Canclini and "migrant subject" by Antonio Cornejo \\ Polar
}

Hugo Herrera Pardo

Universidad Andrés Bello, Chile. Correo electrónico: hugo.herrera.pardo@gmail.com

\begin{abstract}
A través de un contrapunto entre las nociones de "hibridez" realizada por Néstor García Canclini y "sujeto migrante" de Antonio Cornejo Polar, el presente artículo interpreta algunas de las transformaciones experimentadas por la crítica latinoamericana durante la década de 1990. El núcleo problemático del análisis se enfoca en el desplazamiento desde las "metáforas", ligadas a la cultura, a la "metonimia" discursiva que puede advertirse a partir del contrapunto señalado. Para tales efectos, se recurre a algunos elementos de análisis expuestos por Ernesto Laclau en su giro retórico para la discusión política.
\end{abstract}

Palabras clave: hibridez, Néstor García Canclini, sujeto migrante, Antonio Cornejo Polar, latinoamericanismo

By contrasting the notions of "hybridity" proposed by Nestor Garcíaa Canclini and "migrant subject" by Antonio Cornejo Polar, this article interprets some of the changes experienced by Latin American criticism during the 1990s. The core problem in our analysis focuses on the shift from "metaphors", linked to culture, to discursive "metonymy", identified from the counterpoint before mentioned. For this purpose, we use some elements of analysis proposed by Ernesto Laclau in his rhetorical turn for political discussion .

Key words: hibridity, Néstor García Canclini, migrant subject, Antonio Cornejo Polar, latin-americanism

\section{1. “...LA FRAGMENTADA PERO CONTINUA INDETERMINACIÓN DEL HORIZONTE”: INTRODUCCIÓN}

Me propongo realizar en el siguiente artículo una interpretación, siempre tentativa, sobre algunas de las transformaciones experimentadas y debatidas al interior de la crítica literaria latinoamericana a lo largo de la década de los noventa. El punto 
nodal de este propósito lo constituyen dos momentos de la ensayística de Antonio Cornejo Polar en aquella década. Un primer momento es la discusión en torno a "los riesgos de las metáforas" señalados por el crítico peruano en algunas de sus últimas intervenciones en relevantes congresos de la disciplina (JALLA y LASA). El otro momento, y núcleo problemático para canalizar esta interpretación tentativa, se encuentra enfocado en el desplazamiento desde las "metáforas" a la "metonimia", expuesto por el autor de Escribir en el aire (1994) a partir de su proposición de la categoría "sujeto migrante". En su ensayo "Condición migrante e intertextualidad multicultural: el caso de Arguedas", Cornejo Polar al contraponer la categoría de mestizo a la de migrante, expresa:

Dicho sin sutileza: si el sujeto mestizo intenta rearmonizar su disturbado orden discursivo, sometiéndolo a la urgencia de una identidad tanto más fuerte cuanto que se sabe quebradiza, el migrante como que deja que se esparza su lenguaje, contaminándolo o no, sobre la superficie y en las profundidades de una deriva en cuyas estaciones se arman intertextos vulnerables y efímeros, desacompasados, porque su figuración primera es la de un sujeto siempre desplazado. Me atrevería a decir, desde esta perspectiva, que en un caso el sentido último es dialéctico -y tal vez su retórica interna sea sobre todo la de la metáfora- mientras que en el otro los términos serían los del diálogo abierto e inconcluso y su modo preferencial -presumiblemente- el de la metonimia. Aquella establece su eficiencia en la solidez de un espacio clausurado dentro del marco de la similaridad y esta, a la inversa, en la fragmentada pero continua indeterminación de su horizonte (Cornejo Polar 1995: 106).

Pienso que esta contraposición y sus puntualizaciones imantan de modo significativo aquellas transformaciones en la crítica latinoamericana a las que me referí someramente al comienzo y que me propongo especificar en las siguientes páginas. Me interesa tomar como punto de partida para el análisis los significados que pueden desprenderse de ese desplazamiento desde la "metáfora" a la "metonimia" descrito por Cornejo Polar. A este respecto, me valgo de algunos elementos de análisis desarrollados por Ernesto Laclau en su propuesta de un giro retórico para el análisis político, sobre todo algunas precisiones expresadas en su ensayo "Articulación y los límites de la metáfora". El objetivo de Laclau en este ensayo y en otros recopilados póstumamente en Los fundamentos retóricos de la sociedad (2014) es sostener que la retoricidad es constitutiva, y no así un abuso, de la significación, que sin un desplazamiento de carácter tropológico la significación no podría llegar a fundarse. Basándose en el célebre artículo de Gerard Genette "Metáfora y metonimia en Proust" para mostrar que la unidad del texto, su coherencia y cohesión, en otras palabras su narrativa, se constituyen a partir del entrecruzamiento entre metáfora y metonimia, y de modo similar basándose en Roman Jakobson (y su conocido trabajo "Dos aspectos del lenguaje y dos tipos de trastornos afásicos") para mostrar que los movimientos retóricos no solo ocurren al nivel del significado, sino que también del significante, Laclau señala que las mencionadas categorías retóricas, en tanto sostenida interdependencia de combinación (metonimia) y sustitución (metáfora), son parte inherente de la dimensión estructural de la significación. Sostiene Laclau:

La conclusión principal es que las nociones de "analogía" y "contigüidad" que son, respectivamente las bases definitorias de los dos tropos, lejos de ser completamente diferentes en naturaleza, tienden al contrario, a solaparse una a otra. ¿Por qué? Porque 
ambas son transgresiones del mismo principio; a saber, la lógica diferencial asociada al eje sintagmático del sistema de significación. La única distinción que es posible establecer entre ambas figuras es que, en el caso de la metonimia, la transgresión de las localizaciones estructurales que definen la relación de combinación es enteramente visible, mientras que en la metáfora, la analogía ignora completamente esas diferenciaciones estructurales -las asociaciones, como muestra Saussure, pueden moverse en las más variadas direcciones-. En cierto sentido, se puede decir que la metáfora es el telos de la metonimia, el momento en que la transgresión de las reglas de combinación ha alcanzado su punto de no retorno: una nueva entidad que ha nacido nos hace olvidar las prácticas transgresivas en que se basa. Pero sin esas prácticas transgresivas, que son esencialmente metonímicas, la nueva entidad metafórica no podría haber emergido (Laclau 2014: 79).

De este modo, si la retoricidad constituye una dimensión inherente de la significación, se pude hacer extensible entonces a toda práctica significante, puesto que se torna equivalente a la articulación social del sentido. Para Laclau, una de las posibilidades de esta extensión es que la interdependencia entre metáfora y metonimia, entre analogía y combinación, es propio de la "operación política central que llamamos "hegemonía": el movimiento de la metonimia hacia la metáfora, de la articulación contingente a la pertenencia esencial" (Laclau 2014: 80). Precisa el filósofo argentino:

El nombre -de un movimiento social, de una ideología, de una institución políticasiempre es la cristalización metafórica de contenidos cuyos vínculos analógicos son el resultado de ocultar la contigüidad contingente de sus orígenes metonímicos. A la inversa, la disolución de una formación hegemónica involucra la reactivación de esa contingencia: el retorno desde una fijación metafórica "sublime" a una humilde asociación metonímica (Laclau 2014: 80).

De esta manera, Cornejo Polar al proponer una categoría de carácter metonímico para contraponer a los conceptos de tipo metafórico (mestizaje, transculturación, hibridez) se enfrenta a una formación hegemónica, desbaratando su pertenencia esencial al restituir su articulación contingente. El objetivo de este trabajo es, entonces, interpretar este proceso. No obstante, para ello, se torna necesario precisar algunas de las tensiones que emergieron en el campo de la crítica latinoamericana a comienzos de los noventa para contextualizar el panorama frente al que Cornejo Polar proyecta sus últimos escritos. El contrapunto para desarrollar este objetivo será un análisis de algunas de las repercusiones más relevantes que generó la propuesta de "hibridez" del antropólogo argentino Néstor García Canclini. Luego analizaré los dos momentos que experimenta la ensayística de Antonio Cornejo Polar durante la década de los noventa, para finalizar con algunas conclusiones al respecto.

\section{2. "HibRIDEZ": SIGNIFICANTE FLOTANTE}

Noresultaría exageradodecirquelametáforaculturalde “hibridez”, enlaformulación de Néstor García Canclini, resultó ser una de las categorías más problemáticas, y por ende más debatidas y resistidas, en la discusión cultural latinoamericana de fines de siglo XX. Prueba de ello es la abultada y polémica bibliografía que generó. No 
sería exagerado, puesto que "hibridez" vino a introducir un cambio general sobre la frontera de exclusión ${ }^{1}$ del latinoamericanismo, correspondiente a un giro óptico sobre la modernidad y sus procesos, y el cual traería aparejado importantes consecuencias. De modo amplio, se puede apreciar que la construcción del discurso de la identidad latinoamericana se había levantado, esencialmente, sobre una concepción de la modernización como fuerza exterior y dominante a la que lo simbolizado como "lo latinoamericano" resistía. Esta dinámica verticalista de los procesos históricos subyacía a los más relevantes análisis y modelos económicos, culturales y sociales esgrimidos desde las medianías del siglo XIX. Dicha estrategia, forjada a lo largo del gran ciclo histórico del continente, aún persistía y en diversos grados, en el fundamento de las "metáforas culturales" surgidas en el pensamiento crítico y literario latinoamericano durante la década de 1970. Tanto en "Calibán” (R. Fernández Retamar), "Malandraje" (A. Candido), "Fuera de lugar" (R. Schwarz), "Transculturación narrativa” (Á. Rama), "Literaturas Heterogéneas" (A. Cornejo Polar) o "Entre-Lugar" (S. Santiago), los procesos materiales, sociales o económicos globales o modernización -no tanto así sus diferentes respuestas o modernismos- constituían un proceso externo al cual correspondía resistir y subvertir. En ese sentido, la diferencia de fondo entre algunas de las metáforas se encontraba enclavada en la adscripción, implícita o no, a este proyecto, asimismo como en los grados de sedimentación de condiciones esencialistas y teleológicas.

En su elaboración de los procesos de hibridación, García Canclini postula un vuelco sobre esta perspectiva y opta por comprender la modernización latinoamericana "más que como una fuerza ajena y dominante, que operaría por sustitución de lo tradicional y lo propio, como los intentos de renovación con que diversos sectores se hacen cargo de la heterogeneidad multitemporal de cada nación" (García Canclini 2012: 36). Es decir, el objeto de investigación ya no se encontraba puesto en la estructura y el proceso como hechos antagónicos, sino que más bien en la agencia, entendida como modos de apropiación de la modernidad multi-temporal de cada nación. Agencia que estaba pensada con la finalidad de analizar, en palabras del propio García Canclini, el funcionamiento de "los poderes oblicuos envueltos cuando se mezclan las instituciones liberales con los hábitos autoritarios, y los gobiernos social-demócratas con los regímenes paternalistas" (Ibid.: 37). En este aspecto, "entrar y salir de la modernidad", como lo indica el subtítulo del libro, puede comprenderse en el marco de este trabajo como entrar y salir de la frontera de exclusión.

En cierto sentido, este avance hacia la disolución señalada puede advertirse como

Tomo este concepto de Ernesto Laclau (1995) para comprender la construcción diferencial del significado, en la cual lo externo se piensa como amenaza, presente en gran parte de las representaciones culturales de América Latina y que, como se sabe, constituye una de las operaciones eurocéntricas más características. Según Laclau, los límites auténticos de todo sistema significativo en ningún modo son neutrales, sino que en cada caso constituyen una exclusión. Surge así una subversión del sistema significativo, dado que lo que permanece del otro lado del límite de exclusión se presenta como la imposibilidad del lado de acá de dicho límite. En otras palabras, en un sistema significativo los límites son siempre antagónicos. A esa figura del límite excluyente, Laclau lo denomina frontera de exclusión, la cual conlleva a una serie de reflexiones. Entre ellas, por ejemplo, Laclau postula que aquella frontera abre el juego para dos lógicas complementarias: las lógicas de diferencia y equivalencia. Por una parte, todo elemento del sistema mantiene un rasgo diferencial en la medida en que es diferente de los otros. Por otro lado, al pertenecer una serie de elementos al lado interno de la frontera de exclusión, se vuelven de algún modo equivalentes entre sí. Por consiguiente, la identidad de cada elemento al interior del sistema se encuentra constitutivamente dividida: en tanto diferencia al distinguirse de los otros elementos y como equivalencia al entrar en una relación de tal tipo con otros elementos que pertenecen al mismo lado del sistema. 
una instancia lógica. La sedimentación de la positividad identitaria, esencialista y teleológica que venía desarrollándose en el pensamiento crítico y literario latinoamericano, con nitidez desde la década de 1920, había conducido a una concientización sobre la impositiva homogeneidad experimentada al representar lo indígena, lo popular y lo tradicional en el intento de "vaciar" lo nacional o, a nivel macro, lo latinoamericano. Históricamente, estos tres sectores (lo indígena, lo popular $^{2}$ y lo tradicional) fueron apropiados, en diversos grados y momentos, como indicadores de la diferencia latinoamericana. Estrategia diferencial por medio de la cual las elites del continente se apropiaban ontológicamente de estos sectores, llegando a percibirlos como el fundamento del "significante vacío" nación, en un movimiento que los terminaba acercando al discurso universalizante de occidente mucho más que reduciendo la distancia con aquellos, sus "otros" internos. Frente a esta extendida tradición previa verticalista y jerárquica, Néstor García Canclini posiciona el objeto de estudio en una densidad horizontal, optando así por una perspectiva pragmática y no dramática de la modernidad ${ }^{3}$, en tanto que escabulle identificar las culturas como poseedoras de un pasado auténtico. Con esto, el pensador argentino comprende al modernismo, es decir a las respuestas a la modernización como "el modo en el que las elites se hacen cargo de la intersección de diferentes temporalidades históricas y tratan de elaborar con ellas un proyecto global" (García Canclini 2012: 86).

Para pensar esta articulación excluyente característica de la modernización y sus procesos, Néstor García Canclini atiende a tres fenómenos: "reconversión cultural" de saberes y costumbres, la "descolección" de los patrimonios étnicos y nacionales y, por último, la "desterritorialización" experimentada por los sujetos en la modernidad tardía. Estos tres fenómenos se concentran en describir el proceso por el cual las culturas tradicionales lejos de desaparecer, se rearticulan permanente y continuamente en nuevas formas reconvirtiendo así su producción en capital cultural que participa del nuevo circuito económico capitalista. Es a partir de la atención sobre estos fenómenos que García Canclini intenta superar la persistente oposición entre modernización y tradición pues, como se propuso demostrar en su libro, las artesanías y en general los productos de las tradiciones locales no son de ninguna manera ontológicamente incompatibles con la modernización. Pensar la modernidad en este escenario, conduce, en primer lugar, a cuestionar el valor de aquello que la cultura hegemónica excluyó o subestimó para constituirse. El antropólogo argentino se pregunta no sólo si las culturas predominantes -la occidental o nacional, la estatal o la privada- son capaces únicamente de reproducirse, sino que también se interroga por la posibilidad que estas culturas dominantes poseen de crear las condiciones para que sus formas marginales de arte y cultura se manifiesten. Es en este sentido que plantea que:

Una política es democrática tanto por construir espacios para el reconocimiento y el desarrollo colectivos como por suscitar las condiciones reflexivas, críticas, sensibles

Sobre la profundización de este problema basado en la perspectiva de lo popular, puede revisarse el libro de William Rowe y Vivian Schelling Memory and modernity: popular culture in Latin America (Londres: Verso, 1991). Su primera traducción al español data de 1993 (México: Grijalbo).

\footnotetext{
Ocupo los términos con los que Mirko Lauer describe la perspectiva sobre la modernidad adoptada por García Canclini en Culturas híbridas.
} 
para que sea pensado lo que obstaculiza ese reconocimiento. Quizá el tema central de las políticas culturales sea hoy cómo construir sociedades con proyectos democráticos compartidos sin que igualen a todos, donde la disgregación se eleva a diversidad y las desigualdades (entre clases, etnias o grupos) se reduzcan a diferencias (García Canclini 2012: 148).

De este modo y en tanto estrategias, estos fenómenos señalados permiten imaginar los procesos culturales bajo las figuras de movimiento, transformación y coexistencia simultánea de diversos y disímiles sistemas simbólicos. De este modo, la noción de "hibridación/hibridez" pasa a cuestionar la concepción de las identidades culturales basadas en la esencia y el patrimonio. Es a todo este proceso al que García Canclini denomina "hibridación", al cual define, textualmente, como los:

[P]rocesos socio-culturales en los que estructuras o prácticas discretas, que existían en forma separada, se combinan para generar nuevas estructuras, objetos y prácticas. A su vez, cabe aclarar que las estructuras llamadas discretas fueron resultado de hibridaciones, por lo cual no pueden ser consideradas fuentes puras. (...) Se encontrarán ocasionales menciones de los términos sincretismos, mestizaje y otros empleados para designar procesos de hibridación. Prefiero este último porque abarca diversas mezclas interculturales -no sólo las raciales a las que suele limitarse mestizaje y porque permite incluir las formas modernas de hibridación mejor que sincretismo, fórmula referida casi siempre a fusiones religiosas o de movimientos simbólicos tradicionales (García Canclini 2012: 14-15)

Dos consideraciones asoman rápidamente. La primera señala a la "hibridez" como conceptualmente más abarcador que otros de su misma familia categorial, como mestizaje, sincretismo o creolización. En palabras del propio García Canclini, estos tres últimos conceptos constituyen, más bien, una tipología de hibridaciones tradicionales.

La segunda consideración es que, pensados de este modo, los procesos culturales ya no se encuentra localizados en ningún "lugar de origen", asumiendo por tal al territorio considerado de modo esencialista. Tomando en consideración que, bajo una "perspectiva culturalista", frente a la modernidad se había articulado la frontera de exclusión latinoamericanista, es que podemos comprender por qué la propuesta del crítico cultural argentino logra producir un cuestionamiento radical en algunos conceptos tales como democracia ${ }^{4}$, identidad, cultura, diferencia, desigualdad, multiculturalidad, y sobre todo oposiciones binarias o parejas organizadoras de los conflictos en las ciencias sociales como tradición/modernidad, culto/popular, central/ periférico, norte/sur, local/global, dominante/subalterno, "imbricados deslizamientos de categorías" que alteraron radicalmente "la relación dicotómica entre lo uno y lo otro, lo idéntico y lo diferente, lo propio y lo ajeno, lo colonizador y lo colonizado, que fundó la conciencia oposicional y contestataria de América Latina”, en palabras de Nelly Richard (Richard 1997: 345-346)5 . Si la cultura ya no se encuentra

Como él mismo expresa, “una política democratizadora no es sólo la que socializa los bienes ‘legítimos', sino la que problematiza lo que debe entenderse por cultura y cuáles son los derechos de los heterogéneo".

\footnotetext{
Agrega Nelly Richard: "Esta proliferación de márgenes ha creado múltiples interrupciones y discontinuidades en la superficie de representación del poder cultural que accidentaron (fragmentaron, disgregaron) la imagen del Centro, haciendo que dicha imagen ya no sea concebible como un absoluto punto de dominio y control homogéneos. Esta
} 
localizada en ningún lugar estable en términos esencialistas, si la modernización y sus consecuencias ya no se consideran fuerzas antagónicas externas, los conceptos y las parejas organizadoras binarias a las que refiere García Canclini quedaban desarticuladas del "significante vacío" que las había articulado. Esta dirección de análisis llevó a la teoría cultural a cuestionar cada vez más la estructura discursiva que separa lo "popular", "indígena", "tradicional" de lo "culto" en razón del valor. Para García Canclini, de hecho, diferenciar entre los productos de los artistas y de los artesanos constituye una de las más poderosas formas de diferenciación social.

Este cuestionamiento de la estructura del discurso cultural no sólo desestabiliza los conceptos y oposiciones binarias señaladas en el párrafo anterior. La definición de "hibridez" de Canclini cuestiona en sus bases a "fuera de lugar", "transculturación narrativa" y "heterogeneidad cultural", sobre todo al postular que las estructuras denominadas discretas ya fueron ellas mismas resultado de hibridaciones anteriores, por lo cual queda desechada su consideración ontológica como fuentes puras. Fuentes puras que, por ende, constituían una de las piedras de tope más problemáticas de los modelos críticos de Schwarz, Rama y Cornejo. Sobre esta consideración volveremos en el apartado siguiente.

De momento atendamos a otro tipo de desestabilización que "hibridez" produce. En específico me refiero al efecto provocado en disciplinas adyacentes como la antropología y la sociología ${ }^{6}$. La antropología, preferentemente, había posicionado su objeto de estudio en "lo tradicional", entendiendo por ello, de modo fundamental, a los estratos indígenas y campesinos. La sociología, por su parte, había asentado su objeto de investigación en el otro término del par binario, la modernización, centrando sus alcances en los procesos macrosociales y económicos. Atender a los procesos de hibridación como agencia conlleva desestabilizar la constitución disciplinaria tanto de una como de otra, y con ello sus métodos. Como señala Jean Franco, en una de las más reconocidas reseñas del libro de García Canclini:

Culturas híbridas es un libro en busca de un método. Pues aunque su autor favorece una actitud abierta, aún cuando quiere una teoría cultural que no está limitada por falsas oposiciones como las de alta cultura o cultura popular, lo urbano frente a lo rural, lo moderno o lo tradicional, y en tanto tiende a aplaudir la ironía y el pastiche, el juego y la informalidad, frente a todas estas aspiraciones los métodos y el lenguaje de las ciencias sociales constituyen un obstáculo (Franco 2001: 47).

Desarticulación de los conceptos, de las oposiciones binarias, de las metáforas culturales previas, de las disciplinas y sus métodos. Estas son algunas de las consecuencias que produce el agenciamiento como objeto investigativo en los proyectos de apropiación de la modernidad multi-temporal latinoamericana que Néstor García Canclini denomina procesos de hibridación. Sus consecuencias, en tanto, también aparecen como radicales. Dos son, de modo fundamental, sobre las que

nueva fragmentación y disgregación del trazado de autoridad metropolitano ha modificado el esquema binario de jerarquía y subordinación que, bajo la ideología contestataria de las teorías del subdesarrollo, oponía "centro" y "periferia" como localizaciones fijas y polaridades contrarias, rígidamente enfrentadas entre sí por antagonismos lineales" (Richard 1997: 346-347).

6 En concreto, este tema García Canclini lo desarrolla en el apartado "Antropología vs. Sociología", el cual cierra el capítulo 5 ("La puesta en escena de lo popular") de Culturas hibridas. 
hubo mayor consenso en su aspecto crítico: la idea de modernidad y los problemas metodológicos del planteamiento.

En primer lugar, la idea de modernidad. La celebración del híbrido cultural desplegada por García Canclini desmorona la dialéctica concepción de la modernidad con que había trabajado el pensamiento latinoamericano previamente, pero no propone una reelaboración geopolítica de la misma. La visión teórica de la modernidad que el pensador argentino deja entrever corre por los cauces de las interpretaciones mayormente célebres de la modernidad tardía, como lo son las de Marshall Berman, y por sobre todo las correcciones que a ella realiza Perry Anderson, y la interpretación de Jurgen Habermas ${ }^{7}$. Este punto se torna especialmente crítico, al correr en paralelo a una coyuntura que podemos caracterizar como fisura y dispersión teórica de la modernidad. Coyuntura en la que coexisten, por una parte, las teorías posmodernas que expresan la crisis del proyecto moderno en el corazón mismo de Europa y de los Estados Unidos, y las teorías poscoloniales, que hacen lo mismo, pero desde la perspectiva de las colonias que recién lograron su independencia después de la Segunda Guerra Mundial. Compiten entonces, proyectos alternativos a la modernidad como la posmodernidad, el posorientalismo y el emergente posoccidentalismo que comenzaba a organizarse institucionalmente en aquel momento, aunque su precedente puede retrotraerse hacia fines de los sesenta con el surgimiento de los movimientos intelectuales latinoamericanos de liberación (teología, filosofía, pedagogía). La omisión de una postura geopolítica sobre el fenómeno en cuestión en la teoría de García Canclini, inmersa en un ambiente de avasallante ascensión "posmoderna" atravesó el grave peligro de producir las condiciones de aceptación para aquella interpretación de la crisis del proyecto de la modernidad. Este peligro, que acecha a la omisión, puede sintetizarse en el siguiente comentario de George Yúdice:

una centralidad descentrada que procura relegitimarse en un contexto globalizante a través de apelaciones a alteridades, marginalidades, subalternidades, etc. desde sus propios aparatos académicos de producción de saber y con la participación de intelectuales postcoloniales radicados en ellos (Yúdice $2002: 344$ ).

La celebración del híbrido en García Canclini se estrellaba indefectiblemente en ciertos niveles con esta búsqueda de relegitimación llevada a cabo por una "centralidad descentrada". En el plano teórico de la articulación, al modo como entienden este concepto Ernesto Laclau o Stuart Hall, esto venía a significar el ingreso a la frontera de exclusión de fuerzas externas desarticuladoras del antagonismo que había fundado la misma. Donde se puede apreciar este enorme riesgo es en el hecho de que, al desarticular la oposición moderno/tradicional puede mantener, e inclusive enfatizar, las desigualdades sociales, pero a la vez los problemas étnicos, raciales y de clase quedan sublimados. Lo riesgoso de esta sublimación se centraba en la prácticamente nula consideración de la experiencia colonial en la versión de la "hibridez" propuesta

\footnotetext{
En relación a este punto problemático de la idea de modernidad en la hibridación propuesta por Canclini, Edgardo Lander anota: "Parece aquí asumirse que hay un tiempo histórico "normal" y universal que es el europeo. La modernidad entendida como universal tiene como modelo "puro" a la experiencia europea. En contraste con este modelo o estándar de comparación, los procesos de la modernidad en América Latina se dan en forma "contradictoria" y "desigual”, como intersección de diferentes temporalidades históricas (¿temporalidades europeas?)" (Lauder 2003: 27).
} 
por Néstor García Canclini. Precisamente un hecho geopolíticamente ineludible en cualquier evaluación latinoamericana sobre el proyecto de la modernidad.

En segundo lugar, el problema metodológico. Este segundo aspecto constituyó un tópico bastante frecuente en las primeras evaluaciones de Culturas híbridas, o más vale decir, entre la primera aparición de este libro y los libros posteriores de Canclini hasta la reimpresión de su texto, a esas alturas ya devenido clásico, en el año 2012, la cual incluye una nueva introducción que reformula algunas de las críticas más importantes para hacerse cargo del problema. De modo general, el aspecto más problemático refería a la excesiva capacidad descriptiva de la metáfora cultural. Consciente de las críticas, García Canclini religa, muy posteriormente, al nivel descriptivo característico de la metáfora con otros dos niveles complementarios, uno explicativo y otro hermenéutico:

Una dificultad para cumplir estos propósitos es que los estudios sobre hibridación suelen limitarse a describir mezclas interculturales. Apenas comenzamos a avanzar, como parte de la reconstrucción sociocultural del concepto, para darle poder explicativo: estudiar los procesos de hibridación en relaciones estructurales de causalidad. Y darle capacidad hermenéutica: volverlo útil para interpretar las relaciones de sentido que se reconstruyen en las mezclas (García Canclini 2012: 18).

Esta excesiva capacidad descriptiva de la metáfora en su planteamiento origina $l^{8}$, aunada a su ausencia de posicionamiento geopolítico y teórico con respecto a la modernidad confluyen para dar pie a un agudo problema de carácter político. Obliteradas en ella direcciones definidas a nivel metodológico y a nivel teórico sobre la modernidad, "hibridez" expande su imagen fenomenológica hasta el punto de convertirse en un concepto contenedor, una categoría que parece abarcar mucho y así parecer convertirse en la aparente clave para explicar el funcionamiento cultural a nivel global en la modernidad tardía. Inclusive asimismo lo reconoce el propio García Canclini:

Se lo usa para describir procesos interétnicos y de descolonización (Bhabha; Young), globalizadores (Hannerz), viajes y cruces de fronteras (Clifford), fusiones artísticas,

Una de las críticas que llevó a García Canclini a atender las dificultades de la excesiva descripción inherente a su proposición de hibridez fue precisamente la realizada por Antonio Cornejo Polar, en algunos de sus últimos textos (específicamente "Mestizaje, transculturación, heterogeneidad" y, por sobre todo, "Mestizaje e hibridez: los riesgos de las metáforas"). En su respuesta a Cornejo ("Entrar y salir de la hibridación”), Canclini toma en consideración el potencial de transitoriedad que Cornejo ve en el concepto y, que de paso, lo ayuda a escapar de la apoteósica celebración del híbrido solventada en el escaso énfasis en lo contradictorio de los conflictos socio-culturales tras el programa del antropólogo argentino. En dicho texto, Canclini asume que: "En todo caso, pienso que en la década actual se ha hecho bastante para reconocer el carácter contradictorio de los procesos hibrizadores. Esto se está logrando al pasar del simple carácter descriptivo de la noción de hibridación -como fusión de estructuras o practicas discretas- a elaborarla como recurso para explicar en qué casos las mezclas pueden ser productivas y cuando los conflictos siguen operando debido a lo que permanece incompatible o inconciliable en las prácticas reunidas. A los autores citados, debe agregarse la contribución de Cornejo Polar cuando dice que, así como se "entra y sale de la modernidad", también se podría entender de modo histórico las variaciones y conflictos de la metáfora que nos ocupa si habláramos de "entrar y salir de la hibridez" (...). Si se me hubiera ocurrido aplicar a la hibridación este movimiento de tránsito y provisionalidad que en Culturas hibridas coloqué, desde el subtitulo, en relación con los accesos y abandonos de la modernidad, hubiera podido dilucidar mejor cómo los sujetos individuales y colectivos se comportan respecto de lo que la hibridación les permite armonizar y de lo que les resulta inconciliable. De este modo, también se pueden trabajar los procesos de hibridación en relación con la desigualdad entre las culturas y con las posibilidades de apropiarse de varias a la vez en clases y grupos diferentes, y por tanto respecto del poder y el prestigio" (García Canclini 2012: 55). 
literarias y comunicacionales (De la Campa; Hall; Martín Barbero; Papastergiadis; Werbner). No faltan estudios sobre cómo se hibridan gastronomías de distintos orígenes en la comida de un país (Archetti), ni de la asociación de instituciones públicas y corporaciones privadas, de la museografía occidental y las tradiciones periféricas en las exposiciones universales (Harvey) (García Canclini 2012: 13).

Gana en densidad fenomenológica pero pierde notoriamente su capacidad y precisión analítica, al punto que, como puntualiza Abril Trigo,

al abarcar todo no califica nada, con lo cual podríamos preguntarnos que si la hibridez satura todo lo cultural", con lo cual, a renglón seguido, pasa a preguntarse si "¿el adjetivo en culturas híbridas no se reduciría a un puro pleonasmo, a un gesto trivial y tautológico? ¿Qué designa lo híbrido cuando nada es auténtico o, dicho de otro modo, cuanto todo lo es? ¿No sería una coartada más, ante la ausencia de identidades discretas, para crear pivotes emancipatorios? (Trigo 1997: 74).

"Hibridez" se transforma, de este modo, en la gran trampa metodológica de la que nos advertía Edward Said en su famoso ensayo "Travelling theories", tomando un pasaje, a su vez, del trabajo de Raymond Williams "Base y Superestructura en la teoría marxista". Excesiva densidad fenomenológica en desmedro de la capacidad y precisión analítica que arrastran de tal modo contradicciones y tensiones internas, por lo que acaba superponiendo su carga semántica junto a otras metáforas, generando un particular fenómeno de analogía o metáfora en el sentido propuesto por Laclau y, por lo tanto, de vaciamiento de significado o identidad absoluta. Esto se traduce en una distancia entre experiencia y teoría, lo que en el plano estrictamente disciplinar involucra una ontologización del propio campo de estudios. Socialmente, su característica más relevante es, como explicaré luego, su eclosión en una decadencia disciplinaria.

Enfocado al campo del pensamiento crítico literario latinoamericano este aspecto genera una aguda crisis, la cual puede explicarse en los siguientes términos. Ángel Rama expresa que a partir de la segunda década del siglo XX comienzan a surgir una serie de demandas en el campo del pensamiento crítico y literario latinoamericano, las cuales acabarán impulsando una "línea interpretativa tendencial" (Rama 2006: 126). Unos cuarenta años más tarde, este proceso decantará en una aguda renovación del arsenal teórico y metodológico con que hasta ese momento había operado el campo señalado. A juicio de Rama, las demandas que con mayor fuerza recorren ese trayecto formativo son dos: por una parte, la idea de una "metodología derivada de los rasgos históricos específicos latinoamericanos" (124) o, a decir de Gayatri Spivak, un "instrumento de estudio que participa de la naturaleza del objeto de estudio" (Spivak 2013: 330) y, por otra, la adopción de una "perspectiva culturalista" (126). Por tanto, la analogía o identidad metafórica que produce "hibridez" genera una crisis ya que desestabiliza la demanda de una "metodología derivada de los rasgos históricos específicos latinoamericanos" que venía gestándose desde hacía décadas. La reflexión literaria, de hecho, es superficial en el texto de Canclini. Rita de Grandis es quien ha puesto mayor atención a este problema. En su estudio asevera que el punto de vista de Canclini con respecto a lo literario "no es exactamente el de analizar el discurso de textos literarios, y las transformaciones en la naturaleza del material estético", sino que está 
[M]ás bien interesado en los autores y escritores como artistas y lo que hacen con sus textos. García Canclini nos dice, "Hay obras eruditas y a la vez masivas como El nombre de la rosa, temas de debates hermenéuticos en simposios y también "best-seller" (...) En "Cómo interpretar una historia híbrida" menciona al pasar Cien años de soledad y luego alude al realismo maravilloso (69-70). En "Artistas intermediarios y público: innovar o democratizar?" elige a Jorge Luis Borges y a Octavio Paz para ilustrar la crisis "no sólo personal de intelectuales y artistas sino de su papel como mediadores e intérpretes del cambio social" (95). Y a propósito de Octavio Paz manifiesta que "en su obra ha ido creciendo la indignación frente al poder estatal mientras en sus vínculos con el mercado busca una relación productiva, recurriendo a los medios masivos para expandir su discurso" (De Grandis 1997: 39).

El problema es que con esta desarticulación de la "metodología derivada de los rasgos específicos latinoamericanos" la noción de "hibridez" tal como la plantea Néstor García Canclini pasa, a modo de significante flotante, a superponerse a otras metáforas culturales que venían desplegándose en el campo de la discursividad latinoamericana desde la década del setenta, principalmente "transculturación narrativa" y "heterogeneidad cultural". Y también, por otra parte, esta excesiva densidad metodológica arrastraba tanto a la "hibridez" como a las proposiciones de Rama y Cornejo a situarse des-problematizadamente al lado de "mestizaje", justamente la metáfora cultural que, se suponía, aquellas elaboraciones categoriales intentaban superar. El debate sobre esta superposición estaría conducido por dos textos polémicos al respecto escritos por Antonio Cornejo Polar. Sin embargo, antes de pasar a revisar aquellos breves trabajos y el debate que suscitaron, se torna necesario evaluar el último momento de la trayectoria del crítico peruano, la cual puede leerse como un intento de rearticular (al menos parcialmente) algunos de los aspectos problemáticos desarticulados por "hibridez".

\section{De LAS METÁforas CULTURALES A LA METONIMIA DISCURSIVA}

Como revisamos en el apartado anterior, la desarticulación efectuada por García Canclini, tanto de la "perspectiva culturalista" como de la "metodología derivada de los rasgos históricos específicos latinoamericanos" producida por la desfundamentación de una perspectiva crítica sobre la modernidad, generó una severa crisis en la frontera de exclusión de lo simbolizado como América Latina, manifestado de modo fundamental en la desestabilización de sus disciplinas adyacentes (objetos de estudio, categorías y metodologías). El último momento de la trayectoria crítica de Antonio Cornejo Polar puede leerse como el intento de postular dos estrategias para enfrentar la crisis del campo. En estas estrategias Cornejo no intenta reconstruir la frontera, sino que más bien, instalándose desde "el riesgoso pero incitante margen donde yo y el otro se confunden frente al hirviente espejo de un mundo que acoge sin reparos mutaciones y disidencias" (Cornejo Polar 1993: 159), intenta responder críticamente a las fuerzas externas "posmodernas" con la rearticulación y desarticulación de algunas posiciones clave. En efecto, ambas estrategias, simultánea

\footnotetext{
La cursiva en margen es agregada por mí, con el objetivo de establecer sentido con el concepto de frontera de exclusión que he venido desarrollando.
} 
y parcialmente tanto desarticuladoras como rearticuladoras, pueden imaginarse a partir de dos movimientos que las caracterizan y distinguen. La primera de las estrategias es de movimiento centrífugo, y abarca desde su re-evaluación crítica del mestizaje hasta su proposición de la categoría "sujeto migrante"10. La segunda de ellas, de movimiento centrípeto, engloba su texto póstumo y el antecedente directo de éste, un material de trabajo presentado para el encuentro JALLA $1995^{11}$. La primera estrategia puede comprenderse como una des/re/articulación "desde adentro hacia afuera" de algunos conceptos claves con el objetivo tal de que lograran resistir los embates propiciados por la celebración apoteósica de lo híbrido. La segunda, en tanto, opta por comprenderla como una des/re/articulación "desde afuera hacia dentro" del desarrollo latinoamericanista durante gran parte del siglo pasado ${ }^{12}$. En este apartado revisaremos la primera de ellas.

He dicho que en el último tramo de su travesía intelectual, Antonio Cornejo Polar no intenta reorganizar el campo después de la desestabilización suscitada por la metáfora cultural "hibridez", aunque, y al igual que con su formulación de "heterogeneidad cultural", aspira a que "sujeto migrante" sea apta hermenéuticamente para leer un amplio sector de las literaturas latinoamericanas. Más bien, Cornejo Polar, lejos de una postura romántica, lee en esta coyuntura una posibilidad de evaluar críticamente el desarrollo de la disciplina durante las últimas décadas (sobre todo desde el período en que él comenzó a ser parte activa e importante, es decir desde los sesenta) y paralelamente, responder a lo que él considera algunos de los peligros inherentes al proyecto posmoderno. El comienzo de esta senda puede situarse en su severa revisión del debate sobre la teoría literaria hispanoamericana producido en los setenta, a partir del célebre ensayo de Roberto Fernández Retamar. Allí, en dicho texto, considera que tal proyecto fracasó debido a lo abstracto de la demanda, posicionada de manera muy distante de lo histórico específico. En otros términos, Cornejo asume como uno de los principales logros de la discusión de los setenta aquella visión de la historia que no sólo corre linealmente, sino que también "se adensa en el tiempo", como expresará en el ensayo "Una heterogeneidad no dialéctica", reuniendo en un diálogo abierto y, no de manera dialéctica, el entonces/allá y el aquí/ahora. En el reverso de este logro, claro

10 Estos textos corresponden a "Para una teoría literaria hispanoamericana: a veinte años de un debate decisivo", leído a comienzos de 1992 en el congreso "Estado actual de los estudios literarios latinoamericanistas", celebrado en la Universidad de Granada. "El discurso de la armonía imposible (El Inca Garcilaso de la Vega: Discurso y recepción social)", publicado el año 1993, pero leído como ponencia el año anterior en España en el marco de un congreso sobre el V centenario de la llegada de Colón a América. "Ensayo sobre el sujeto y la representación en la literatura latinoamericana (algunas hipótesis)", publicado también el año de 1993 y que al año siguiente aparecería reproducido parcialmente como "Introducción" de su último libro Escribir en el aire. Ensayo sobre la heterogeneidad sociocultural de las literaturas andinas. Y también incluyo en esta estrategia sus dos últimos artículos, relativos a la categoría de "sujeto migrante": "Condición migrante e intertextualidad multicultural: el caso de Arguedas" (1995) y "Una heterogeneidad no dialéctica: sujeto y discursos migrantes en el Perú moderno" (1996).

11 En específico, me refiero a los textos "Mestizaje, transculturación, heterogeneidad" (1995), y "Mestizaje e hibridez. Los riesgos de las metáforas (Apuntes)" (1997).

12 Para realizar esta distinción que interprete ambas instancias paralelas del último tramo de la carrera crítica de Cornejo Polar, me valgo del siguiente pasaje del artículo "Condición migrante e intertextualidad: el caso Arguedas": "Subrayo en este orden de cosas la dinámica centrifuga del discurso migrante y su reivindicación de la múltiple vigencia del aquí y el allá y del ahora y el ayer, casi como un acto simbólico que en el instante mismo en que afirma la rotundidad de una frontera la está burlando, y hasta escarneciendo, mediante la fluidez de un habla que se emite desde cualquiera de sus lados y siempre de manera eventual, transitoria, repitiendo la condición viajera del sujeto que la dice" (105-106, la cursiva es mía). 
está, se sitúan los problemas y límites de los grandes proyectos de historia social de las literaturas latinoamericanas de las décadas de los setenta y ochenta (Ana Pizarro, Alejandro Losada). Tras ratificar su postura por esta densificación de la historia y sus cauces es que Cornejo elaborará una estrategia de movimiento centrífugo con tal de "historiar la sincronía" y así encarar algunos de los puntos críticos provocados por la apoteosis del híbrido cultural.

Recalco, en esta intervención Cornejo no se esfuerza por re-territorializar completamente la frontera, de hecho, parece entender la fragmentación y dispersión del campo propiciado por la "hibridez" como un suceso lógico en relación a lo que el mismo venía elaborando con su hipótesis de las "Literaturas Heterogéneas"13. De hecho, uno de los caminos a los que condujo el "fracaso de la teoría hispanoamericana" fue el de advertir la índole entreverada y dispersa de nuestra identidad, olvidando con ello la utopía de las identidades fijas y estables. En este sentido, Cornejo concuerda con García Canclini en no seguir pensando la identidad como patrimonio, "como una obsesión que nos defina para siempre", sino como pluralidad múltiple y hasta contradictoria. Sin embargo, no coincide con el antropólogo argentino en ver "en la migración la celebración casi apoteósica de la desterritorialización”, pues esta perspectiva sin un fundamento crítico geopolítico de la modernidad, y sumado a su opción sincrética de los procesos culturales, subliman los conflictos (de raza, etnia y clase) adensados en la historia latinoamericana, conjunción que produce una merma indefectible a efectos de una visión e interpretación del continente sobre las causalidades y consecuencias de los universalismos occidentalizantes.

El problema de fondo de este afán sincrético, que sublima las experiencias culturales en un espacio de resolución armónica, es que constituye una aporía con respecto a la defensa de la democratización de la cultura que buscaba García Canclini en su estudio. Sin ir más lejos, demuestra la imposibilidad de pensar una eventual democratización cultural en el marco de la globalización bajo la figura de una síntesis conciliante. Porque en efecto, gran parte del esfuerzo de Cornejo radica en reiterarnos que todo afán sincrético y conciliante atenta contra un contexto como el latinoamericano, marcado por "el carácter de una realidad hecha de fisuras y superposiciones, que acumula varios tiempos en un tiempo, y que no se deja decir más que asumiendo el riesgo de la fragmentación del discurso que la representa y a la vez la constituye" (Cornejo Polar 1993: 9). De este modo, y en primer lugar, ante la rearmonización imposible que subyace a la condición y el sujeto mestizo, Cornejo Polar pretende "historiar la sincronía" que propone el esparcimiento y contaminación del lenguaje tras la condición y el sujeto del migrar. Acto éste comprendido cercanamente a:

algo así como nostalgiar desde un presente que es o debería ser pleno, las muchas instancias y estancias que se dejaron allá y entonces, un allá y un entonces que de pronto se descubre que son el acá de la memoria insomne pero fragmentada y el ahora que tanto corre como se ahonda, verticalmente, en un tiempo espeso que acumula sin

Mabel Moraña en su artículo "Escribir en el aire. "Heterogeneidad" y Estudios culturales" evalúa los límites de la categoría "heterogeneidad" en el último libro publicado por Cornejo Polar. La autora dedica la parte final de su trabajo a reflexionar sobre cómo en algunos pasajes de los análisis dedicados por Cornejo a diversos textos de las literaturas andinas "nociones como heterogeneidad y sistema parecen interferir en el análisis más que nutrirlo o sustentarlo" (Moraña 1995: 282). 
sintetizar las experiencias del ayer y de los espacios que se dejaron atrás y que siguen perturbando con rabia o con ternura (Cornejo Polar 1995: 103).

No puede dejar de señalarse con respecto al tema de la fragmentación y discontinuidad de los discursos que, indefectiblemente, "sujeto migrante" emerge a partir de algunos de los aspectos más problemáticos de "heterogeneidad", reconocidos posteriormente por Cornejo Polar. En su breve material de trabajo "Mestizaje, transculturación, heterogeneidad" (1994b) asume con respecto a su propia categoría:

se requiere problematizar intensamente la condición histórica de la heterogeneidad: en ella actúan discursos discontinuos que configuran estratificaciones que en cierto modo verticalizan y fragmentan la historia, tal como se aprecia en la re-enunciación de los mitos de Huarochirí en El zorro de arriba y el zorro de abajo, por ejemplo (Cornejo Polar 1994b: 370).

En segundo lugar, frente al sentido dialéctico de la gesta del mestizo, Cornejo Polar opta por la condición dialógicamente abierta e inconclusa del migrante. Por último, y ante el modo retórico de la "metáfora" tras la perspectiva culturalista del mestizo que "establece su eficiencia en la solidez de un espacio clausurado dentro del marco de la similaridad", el crítico peruano avanza en su posición y basa el modo discursivo del migrante en la "metonimia", la cual establece su eficiencia, a la inversa que la metáfora, "en la fragmentada pero continua indeterminación de su horizonte" (Cornejo Polar 1995: 106). De la cultura al discurso, de la nación al sujeto, de la frontera al margen, de la metáfora a la metonimia; Cornejo utiliza estratégicamente la desarticulación del campo de la discursividad optando (más que reconstruirlo) por rearticular posiciones clave desde un "poroso y ríspido" margen que historice las condiciones de emergencia y resistencia de lo uno y lo otro, lo propio y lo ajeno, la identidad y la alteridad.

La elaboración mas sistemática y extensa a estas problemáticas las trabaja Cornejo Polar en su último libro publicado en vida, Escribir en el aire. Allí descubre que después de todo, en Los ríos profundos, la novela por la cual lleva a cabo las reflexiones anteriormente citadas, el discurso se aproxima a ser un espacio conflictuado por múltiples voces a través de un diálogo que no siempre termina por ser dialéctico - según lo advertido por Bajtín en variadas ocasiones- debido a que bien puede prescindir de la síntesis superadora y acogerse al "coexistir intervinculante" pero no totalizador, en un espacio que per se "parece o carece de límites o ser inclusive en su centro- sólo un abierto, inestable y poroso borde"(Cornejo Polar 1994: 199). Este hecho lo lleva a indagar nuevamente a esos sujetos en las novelas de Arguedas, en especial su última novela, "El zorro de arriba, el zorro de abajo", y a construir la categoría de sujeto migrante, que al introducir nuevos ejes semánticos supera el sincretismo desigual a favor de la cultura colonizadora del sujeto mestizo, e instaura el debate de la identidad latinoamericana fuera del planteamiento dialéctico dominante por décadas en la crítica literaria latinoamericana ${ }^{14}$. Cabe mencionar que deconstrucciones de la categoría "transculturación narrativa", con base en la intención
sincrética de la misma, tales como las de Alberto Moreiras y Silvia Spitta de igual modo parten de este hecho que
Cornejo señala en sus últimos trabajos con respecto a Arguedas. 
Tengo para mí que a partir de tal sujeto, y de sus discursos y modos de representación, se podría producir una categoría que permita leer amplios e importantes segmentos de la literatura Latinoamericana -entendida en el más amplio de sus sentidos- especialmente los que están definidos por su radical heterogeneidad. Como se sabe son varias las categorías que se han usado para dar razón de este enredado corpus. Sin ánimo de sustituirlas, aunque algunas como la de mestizaje parecen haber agotado casi toda su capacidad iluminadora, deseo explorar. La pertinencia y la efectividad de esta otra categoría, la de migración y sus derivados, que casi no ha sido empleada en relación a esta problemática (Lauer, 1989). Sospecho que los contenidos de multiplicidad, inestabilidad y desplazamiento que lleva implícitos, y su referencia inexcusable a una dispersa variedad de espacios socio-culturales que tanto se desparraman cuanto se articulan a través de la propia migración, la hacen especialmente apropiada para el estudio de la intensa heterogeneidad de buena parte de la literatura latinoamericana (Cornejo Polar 1996: 838).

Al menos dos implicancias asoman con la estrategia metodológica empleada por Cornejo Polar de situar a un mismo e indesligable nivel tanto al sujeto, como a la mímesis y el discurso. La primera implicancia es residual. Al concebir al sujeto, ya sea individual o colectivo, como una construcción en relación tanto con otros sujetos, como también en su relación con el mundo, o en otros términos, un sujeto acogido al coexistir intervinculante pero no totalizador, Cornejo rescata y activa una concepción de la subjetividad que ya asomaba en sus trabajos de la década del setenta (aunque formalizado más claramente en los trabajos de Silviano Santiago).

$\mathrm{Y}$ en segundo lugar, rearticular desde el sujeto una posición contra-hegemónica frente a la celebración del híbrido implica avanzar en una de las limitantes de la "reconversión cultural" postulada por García Canclini. En efecto, sin lugar a dudas puede apreciarse como una de las grandes ventajas tras el pensar el movimiento cultural como la producción de bienes simbólicos que se intercambian y redistribuyen, y que crean un capital cultural que puede ser reinvertido, el hecho de que contribuye a desmitificar un concepto de cultura. La desmitifica en tanto rompe con la noción romántica de la creación. No obstante, su gran desventaja consistía en que esta reconversión permanente de bienes simbólicos no permitía abordar el problema de la subjetividad, en tanto su énfasis se encontraba puesto en el agenciamiento. En este sentido puede advertirse la validez de la elección de Cornejo; la categoría de sujeto a la vez que constituye, sin dudas, una de las categorías centrales de la modernidad, es también una de las categorías sobre las cuales el pensamiento social occidental ha sido más escurridizo. Norbert Lechner nos señala que dos fenómenos históricos corrieron paralelo al avance de las ciencias sociales en la modernidad: la "des-subjetivación de la reflexión" y la "des-materialización de lo social" 15 . Recuperar al sujeto e historiar su sincronía tras las representaciones construidas en los discursos permite reinstalar la condición colonial para llenar ese vacío de perspectiva crítica sobre la modernidad dejado por la reflexión tras Culturas hibridas. Condición colonial sobre la cual debe pensarse toda reflexión abarcadoramente crítica de la modernidad, toda reflexión, no sólo un planteamiento desde ex colonias formales del imperialismo moderno en sus diversas fases. Las entreveradas consecuencias del sujeto en la modernidad andina

El desarrollo ampliado de esta reflexión puede encontrarse en la primera parte del libro de Lechner Las sombras del mañana. La dimensión subjetiva de la política (2002). 
son evaluadas extensamente en Escribir en el aire, en una reflexión que alcanza desde la escena del "diálogo de Cajamarca" hasta el sujeto de la poesía vallejiana.

No obstante las alternativas que supuso las implicancias tras la defensa de la subjetividad, la categoría de sujeto migrante sólo alcanza a esbozar sus direcciones en los últimos trabajos de Cornejo Polar. En otras palabras, el crítico peruano logra dejar entrever las capacidades teóricas de la "metonimia discursiva", mas no alcanza a señalar sus aptitudes hermenéuticas y potencialidades analíticas más concretas, en casos de estudio más elaboradamente detallados y específicos. Justamente allí radica el intento por extender las capacidades de la categoría en trabajos de críticos posteriores, como los de Abril Trigo o Carlos García-Bedoya, entre otros. Comentado este movimiento del último tramo intelectual de Cornejo Polar, pasemos a revisar su movimiento complementario, me refiero a la dispersión centrípeta tras sus breves textos evaluadores de las metáforas culturales del "gran proyecto epistemológico de los setenta".

\section{LOS RIESGOS DE LAS METÁFORAS: "DECADENCIA DISCIPLINARIA"}

El segundo momento que puede distinguirse dentro del tramo final de la trayectoria intelectual de Cornejo Polar, y paralelo a su reflexión sobre la condición y sujeto migrante, puede comprenderse bajo la figura de un movimiento centrípeto. Es una estrategia, simultánea y parcialmente, tanto desarticuladora como rearticuladora en un desplazamiento "desde afuera hacia adentro". El texto más reconocido de este momento es el póstumo "Mestizaje e hibridez: los riesgos de las metáforas", leído en ausencia del autor durante el encuentro LASA 1997. Sin embargo, un antecedente directo de las problemáticas que el crítico peruano apunta en su último texto es un material de trabajo preparado para JALLA 1995, y publicado previamente en el número 40 de la RCLL, "Mestizaje, transculturación, heterogeneidad" (1994). En ambos apuntes Cornejo expresa su escepticismo frente al viaje de los conceptos por diversas disciplinas del conocimiento y diferentes situaciones históricas específicas. No obstante, en su ensayo póstumo el autor adiciona un segundo problema al debate: las condiciones materiales de los estudios literarios latinoamericanos hacia fines de siglo veinte. Describiré brevemente ambos planteamientos expuestos por Cornejo Polar para luego problematizarlos.

En torno a las travesías llevadas a cabo por los conceptos, cruzando disciplinas y contextos históricos, Cornejo explora su descreimiento al respecto en tres casos: en los préstamos semánticos interdisciplinarios (como en "mestizaje", "hibridez" o "transculturación"), en la "categorías que parecen sustentarse en el propio ejercicio crítico" (como "literatura alternativa", "literatura diglósica" y su propia noción de "literaturas heterogéneas") y categorías extraídas del mismo espacio de experiencia del objeto de estudio (como la utilización de conceptos indígenas para teorizar ese nivel de experiencia). De la primera problemática, Cornejo Polar objeta su grado inherente de ideologización, el cual inevitablemente se desplaza de alguna u otra forma junto a los conceptos y que, en el caso del contexto cultural latinoamericano, había empujado a la apreciación de que aparentemente todo habría quedado armonizado "dentro de espacios apacibles y amenos (y por ciertos hechizos) de nuestra América" (Cornejo Polar 1997: 868). Con respecto al segundo grupo problemático no se muestra menos 
escéptico. Inclusive la contemplación crítica de aquellas, aunadas a las del grupo anterior, le valen para aseverar que

[N]inguna categoría crítica devela la totalidad de la materia que estudia y -sobre todo- la categoría en cuestión corresponde a un orden de distinta índole con relación a esa materia. Para seguir con lo evidente, ninguna de las categorías mencionadas resuelve la totalidad de la problemática que suscita y todas ellas se instalan en el espacio epistemológico que -inevitablemente- es distante y distinto (Cornejo Polar 1997: 868).

El tercer grupo problemático escogido para atisbar la crisis conceptual, grupo en el cual ensaya la articulación de realidades específicas a categorías consustanciales a ellas, tampoco muestra, a juicio del autor, una salida al problema. A pesar de que inicialmente la idea le entusiasma, acaba señalando que admira "su capacidad hermenéutica" pero no llega "a observar su rendimiento teórico", para finalizar asumiendo resignadamente "que tal vez en el fondo la relación entre epistemología critica y producción estética sea inevitablemente metafórica" (Cornejo Polar 1997: 868).

A partir de este punto, la crítica a los inevitables riesgos de los préstamos semánticos en diversas instancias prágmáticas lo lleva, tangencialmente, a reflexionar y advertir sobre las condiciones materiales de los estudios literarios latinoamericanos. Para ello Cornejo enumera algunos de los aspectos que le parecen más problemáticos, entre los que indica: la difícil convivencia de textos y discursos en español y en portugués (y eventualmente en lenguas amerindias) con la incontenible diseminación de textos críticos en inglés (o en otros idiomas europeos), el "excesivo desnivel de la producción crítica en inglés que parece -bajo viejos modelos industriales- tomar como materia prima la literatura hispanoamericana y devolverla en artefactos críticos sofisticados", el fenómeno de la circularidad de la bibliografía en espacios hegemónicos de conocimiento, problema traducido en la "preferencia por el canon teórico posmoderno". La subdivisión de la disciplina de los estudios literarios latinoamericanos entre la reflexión construida en lenguas como español y portugués frente a la construida en inglés, con innegables y severos problemas de comunicabilidad entre ellas. Relacionado a esto último, el crítico también indica la diglosia jerárquica de los estudios de la literatura hispanoamericana, en favor de la producción en inglés, el "declive del empleo del español en el mundo académico", la endogamia de las actividades académicas en inglés ("me temo mucho que los estudios culturales, poscoloniales y/o subalternos no han calibrado lo que implica el practicar esas disciplinas en una sola lengua, cualquiera sea el idioma de los discursos examinados"), los, por lo general, históricamente solapados problemas de las traducciones, tanto a nivel discursivo como material, la "falsa universalización de la literatura a partir del instrumento lingüístico con el que se trabaja", la precarización de las condiciones materiales para el desarrollo de la crítica literaria (y las humanidades en general) en América Latina, argumentado que las

dictaduras primero, con las censuras o métodos harto más brutales, y el neoliberalismo, después, con su política de pauperización de las instituciones culturales públicas (universidades, bibliotecas, archivos), prácticamente han destruido las bases materiales para el desarrollo de la disciplina, aunque también hay que reconocer la situación disímil de cada país y las obvias diferencias de proyectos grupales y personales (Cornejo Polar 1997: 870). 
Junto a lo anterior, habría que agregar además, la reestructuración y privatización experimentada por las universidades latinoamericanas y, derivado de esto último, de igual modo debe adicionarse lo que Lewis Gordon define como el "crecimiento de la clase de gestión académica", lo que a su juicio "ha sido tal vez el fenómeno más catastrófico de las universidades modernas. Quizás sea una consecuencia inevitable de los procesos sociológicos modernos de burocratización y colonización de las idiosincrasias del conocimiento, como el camino para llegar desde su erupción hasta su producción" (Gordon 2013: 26).

El problema de fondo que subyace a las dos problemáticas atendidas por Cornejo en su última intervención (travesías de los conceptos y problemas materiales de la disciplina) y que por lo tanto las relaciona en su base, podemos comprenderlo como una serie bastante férrea de separaciones o particiones. Estas particiones expresan, sin lugar a dudas, la fragmentación más enfática experimentada por "el deshilachado y poco honroso final" advertido por el crítico peruano, debido por sobre todo a los múltiples niveles en que la separación se manifiesta. A partir del texto de Cornejo, y del extenso debate suscitado por ellos, podemos advertir las particiones expresadas entre: A) "una densa capa de significación que engloba y justifica cada concepción de las cosas", y una "simple declaración de amenidad e impertinencia de las categorías empleadas"; "subterráneas relaciones que se dan entre los diversos estratos socio-culturales de América Latina"; B) las "subterráneas relaciones que se dan entre los diversos estratos socio-culturales de América Latina", y "los conflictos y contradicciones" ("todo habría quedado armonizado dentro de espacios apacibles y amenos -y por cierto hechizos-, de nuestra América”); C) el "anclaje semántico de las categorías", y su viaje por distintas disciplinas; D) la Capacidad hermenéutica, y el Rendimiento teórico; E) el rendimiento teórico de las categorías, y la totalidad de la problemática en la que se insertan ("todas ellas se instalan en el espacio epistemológico que - inevitablemente- es distante y distinto"); F) la Epistemología crítica, y la Producción estética [Los índices comprendidos entre A y F se desprenden del texto póstumo de Antonio Cornejo Polar, anteriormente señalado]; G) el "Dispositivo de conocimiento académico, latinoamericanismo", y el "Campo de experiencia, Latinoamérica"; H) Proyectos críticos, y Contextos geopolíticos específicos; I) Teoría, razón, conocimiento, mediación, y Práctica, materia, realidad e inmediatez [G, H e I se desprenden del artículo de Nelly Richard (1997)]; J) Academia, y Esfera pública; K) Textualidad, y Procesos socio-culturales [J y K están tomados del artículo de Martín Lienhard (1999)]; L) los "objetos de reflexión crítica-teórica", y el "lugar de producción teórica" [L está tomado del ensayo de John Beverley, (2002)].

A mi juicio, estas son las separaciones o particiones mayormente englobadoras de la problemática tras el debate provocado por el momento último del trabajo crítico de Cornejo Polar. Por su nivel de determinismo ontológico, entiendo esta discusión - tomando el término de Lewis Gordon- como "decadencia disciplinaria". El propio Gordon define al fenómeno aludido en los siguientes parámetros:

La emergencia de las disciplinas a menudo ha dado paso al olvido de sus ímpetus sobre los seres vivos y de su rol crucial respecto a la manutención y transformación de las prácticas productoras de conocimiento. Los resultados de esto son tipos especiales de decadencia. Uno de ellos es la decadencia disciplinaria. La "decadencia disciplinaria" es la ontologización o reificación de una disciplina. De esta manera, tratamos a nuestra 
disciplina como si nunca fuera a cambiar o -en algunos casos- morir (...) La decadencia disciplinaria, como lo hemos visto, es el proceso de decaída crítica dentro de un campo o disciplina. En estos casos, el proponente ontologiza su disciplina más allá de su ámbito. Así, un científico decadente crítica a las humanidades por no ser científicas; un académico literario decadente crítica a los científicos y científicos sociales por no ser textuales o literarios; un científico social decadente tropieza en dos direcciones: al criticar a las humanidades por no ser científicas sociales o a las ciencias sociales por no ser científicas como, digamos, la física o la biología. Y, por supuesto, el historiador decadente critica a todos por no ser históricos, mientras el filósofo decadente critica a todos por no ser filósofos. La dimensión pública de la evidencia está aquí subordinada a las disciplinas que, literalmente, funcionan como si fueran el mundo. Así, por tanto, otra disciplina o campo pueda ofrecer evidencia de los contrario, esta podría ser ignorada por la simple razón de no ser el punto de vista de la disciplina propia (Gordon 2013: 18-60).

Tras el debate desatado por la intervención póstuma de Cornejo Polar se produce una discusión similar a la descrita por Lewis Gordon. Los latinoamericanos neoarielistas (como Raúl Bueno) atacan la producción crítica sobre la literatura latinoamericana escrita en inglés. Los que trabajan desde esa posición-esencialmente Norteamérica- defienden la utilización de sus préstamos semánticos y terminológicos (como Beverley y la subalternidad) frente a un agotamiento del aparato crítico del hispanoamericanismo. Los que se sienten atacados por la acuñación de conceptos prestados (como García Canclini) recurren a la etimología para resignificar sus posiciones. Sin embargo, detrás de toda estos reclamos que corren paralelamente, casi sin llegar a encontrarse de modo tangencial, se encuentra ontologizada la historia y, junto a ella, las coacciones materiales y disciplinantes detrás de cada disciplina pensadas como dispositivo de poder. De hecho son escasos los polemistas que se hacen cargo de este problema, Nelly Richard y Martin Lienhard entre ellos. En otros términos, tras estas separaciones o particiones que encubren y solapan todo un entramado jerárquico disciplinante subyace una especie de determinismo ontológico, manifestado en lo que, a juicio de Edgardo Lander, resulta ser una de las eficacias naturalizadoras del conocimiento mayormente efectivas producidas por el pensamiento occidental:

Se trata de dos dimensiones que tienen orígenes históricos diferentes, y que sólo adquieren su actual potencia naturalizadora por la vía de su estrecha imbricación. La primera dimensión se refiere a las sucesivas separaciones o particiones del mundo de lo "real" que se dan históricamente en la sociedad occidental y las formas como se va construyendo el conocimiento sobre las bases de este proceso de sucesivas separaciones. La segunda dimensión es la forma como se articulan los saberes modernos con la organización del poder, especialmente las relaciones coloniales/ imperiales de poder constitutivas del mundo moderno. Estas dos dimensiones sirven de sustento sólido a una construcción discursiva naturalizadora de las ciencias sociales o saberes sociales modernos (Lander 2003: 13-14).

La paradoja detrás de esta ontologización de la disciplina, que en el fondo resulta ser una entronización del saber académico es que, tras la extensa búsqueda de una "metodología derivada de los rasgos históricos específicos" para el estudio de las literaturas latinoamericanas durante gran parte del siglo $\mathrm{XX}$, se desatendió lo que podría definirse -en contraposición a lo anterior- como una "ética y una epistemología 
derivada de las coacciones materiales del tejido discursivo, institucional y sociohistórico específico latinoamericano". La paradoja es que mientras se buscaba "un instrumento que participara de la naturaleza del objeto de estudio" (Spivak 2013: 330), se producía una tácita distancia sobre el cuestionamiento al estatus epistemológico de la constitución discursiva disciplinar. La naturaleza del objeto de estudio se aleja de la naturaleza de la organización del poder que le subyace. En otras palabras, la búsqueda de una metodología derivada de los rasgos históricos del continente se produjo atendiendo tendencialmente a una de las dimensiones del occidentalismo, i.e. la jerarquización etnocéntrica de diferencias, pero no se atendió la segunda de las dimensiones, la cual incluso subyacería a la anterior, y es la que refiere al despliegue del poder y el conjunto de sus coacciones, despliegue que inevitablemente es tanto material como simbólico. Como expresa Fernando Coronil, lo que caracteriza al occidentalismo no es tan sólo "que moviliza a las representaciones estereotipadas de sociedades no-occidentales, ya que la jerarquización etnocéntrica de diferencias no es privilegio exclusivo del mundo occidental, si no que dicho privilegio está íntimamente conectado con el despliegue del poder global de occidente" (Coronil 1999: 130).

En este sentido, y complementando la proposición de Lewis Gordon, toda "decadencia disciplinaria" constituye también una fisura para atender el complejo entramado disciplinante que organiza la administración de los saberes.

En el comentario final de su intervención póstuma, Cornejo advierte sobre el "deshilachado y poco honroso final de hispanoamericanismo". En el marco de lo expuesto anteriormente la expresión señalada puede comprenderse del modo siguiente: el prolongado e histórico silencio sobre una ética y una epistemología basada en las coacciones materiales de la disciplina, subyacente a la metodología histórica, explosiona con la crisis social (privatización de las universidades, burocratización y colonización del conocimiento) y simbólica (agotamiento del aparato conceptual) que la disciplina latinoamericanista sufre en la década de los noventa. Esta falta de reflexión material ligada al poder contribuye notoriamente para que otros proyectos críticos emergentes del período -los cuales no sólo tenían categorías y una metacrítica para hacer frente a esta problemática sino que por sobre todo una base institucional poderosa- avanzaran hacia posiciones más dominantes al interior del latinoamericanismo, provocando su reorganización y, con ello, el cierre de un ciclo en el pensamiento crítico y literario latinoamericano. Estos proyectos críticos que fundamentalmente emergen, se consolidan y compiten durante este período son: A) los estudios sobre la cuestión de género (que ya venían desplegándose con fuerza desde comienzos de los ochenta con las instituciones, y las publicaciones impulsadas por Julieta Kirkwood); B) la crítica cultural (representada, entre otros, por Alberto Moreiras, Nelly Richard, Beatriz Sarlo); C) los estudios subalternos (entre los que se contaban John Beverley, Ileana Rodríguez y, en general, los miembros del Latin American Subaltern Studies Group); y D) los estudios poscoloniales (en el cual se cuentan una serie de investigadores reunidos mayoritariamente en este período, en lo que se denominó el grupo de la modernidad/colonialidad $(M / C)$; Walter Mignolo, Edgardo Lander, Aníbal Quijano, Enrique Dussel, Catherine Walsh, Javier Sanjinés, Fernando Coronil, Ramón Grosfoguel, Nelson Maldonado Torres y Santiago CastroGómez, entre los miembros más reconocidos).

Es debido a lo sostenido hasta acá que el deshilachado y poco honroso final al que aludía Cornejo Polar en su intervención póstuma puede comprenderse como la crisis, 
hacia fines de la década de los noventa, de la "línea interpretativa tendencial" y sus dos demandas dominantes, postuladas por Ángel Rama y comentadas más atrás. De la cultura al discurso, de la nación al sujeto, de la frontera al margen, de la metáfora a la metonimia, buena parte de la historia de la crítica latinoamericana del siglo veinte se adensa en aquellos desprendimientos.

\section{5. “...LA FRAGMENTADA PERO CONTINUA INDETERMINACIÓN DEL HORIZONTE”: CONCLUSIÓN}

Ernesto Laclau señala que "cualquier analogía tiene una tendencia natural a confundirse con una metáfora; la relación de contigüidad se convierte, a través de asociaciones persistentes, en una de analogía" (Laclau 2014: 94). Es decir que toda articulación contingente pasa a convertirse, por medio de vínculos sostenidos, en una pertenencia esencial. La cadena "hibridez-mestizaje-transculturaciónheterogeneidad" se había convertido en una reagregación metafórica que había acabado solapando las pluralidades metonímicas, siendo una de las expresiones de este hecho la defensa reificada de la disciplina. De esta manera, podemos interpretar que la intención de Cornejo Polar con la proposición de la categoría "sujeto migrante" fue restituir lo que Ernesto Laclau denomina "la pluralidad sintagmática de espacios de enunciación", de modo tal de abogar por la contingencia ante la instrumentalización metodológica y los esencialismos, en el marco de la disciplina, y ante la crisis de la categoría nación y sus grandes relatos, en el marco socio-político ${ }^{16}$. La combinación pluralista de espacios de enunciación pensada para el "sujeto migrante" no permite la absorción analógica (como sí lo permite "hibridez"), de allí que para definir al migrante Cornejo Polar utilice descriptores tales como "quebradiza" para señalar a la identidad, "esparcimiento" para referir a su lenguaje, "vulnerables, efímeros y desacompasados" para calificar a los intertextos que produce, "desplazado" para interpelar al sujeto y "abierto e inconcluso" para definir el aspecto dialógico que le es propio. Finalmente, "la fragmentada pero continua indeterminación del horizonte" es un alegato para transformar la naturaleza de la elaboración democrática, transformando el vínculo histórico entre tareas y agentes.

\section{OBRAS CITADAS}

Beverley, John. 2002. "Algunas observaciones sobre el último ensayo de Antonio Cornejo Polar y el futuro del hispanoamericanismo". Comp. Schmidt-Welle, Friedhelm. Antonio Cornejo Polar y los estudios latinoamericanos. Pittsburgh: IILI. 285-288.

\footnotetext{
El siguiente párrafo de Gareth Williams servirá para ilustrar rápidamente la crisis de la categoría nación y sus grandes relatos en América Latina, hacia finales del siglo XX: "el ciclo de luchas de liberación nacional que siguieron a la revolución cubana, la intensificación de los antagonismos de la guerra fría, la emergencia de las dictaduras militares como guardianes de los intereses de la elite, en contraste con la creciente desestabilización popular durante los años 1960 y 1970 en el Cono Sur, las guerras de los años 80s en América Central, el fracaso del modelo de industrialización y substitución de importaciones y el eclipse final de la izquierda nacional-popular (incluyendo por supuesto, la derrota electoral de los sandinistas en 1990), expresan las formas en las cuales la lucha por la estabilización de la categoría de pueblo y por organizarla a través de narrativas que la interpelan desde un supuesto destino histórico universal, han caído ahora en lo que Néstor García Canclini ha referido como el eclipse del guión nacional en América Latina y sus grandes narrativas" (Williams 2008: 57).
} 
Cornejo Polar, Antonio. 2003. Escribir en el aire: ensayo sobre la heterogeneidad sociocultural en las literaturas andinas. Lima-Berkeley: CELACP. 1978. "El indigenismo y las literaturas heterogéneas: Su doble estatuto sociocultural". Revista de Crítica Literaria Latinoamericana 7/8: 7-21. 1999. "Para una teoría literaria hispanoamericana: A veinte años de un debate decisivo". Revista de Crítica Literaria Latinoamericana 50: 7-12. 1997. "Mestizaje e hibridez: los riesgos de las metáforas. Apuntes". Revista iberoamericana 200: 341-344.

1995. "Condición migrante e intertextualidad multicultural: El caso de Arguedas". Revista de crítica literaria latinoamericana 42: 101-109.

1994. Escribir en el Aire. Ensayo sobre la heterogeneidad socio-cultural en las literaturas andinas. Lima: Horizonte.

. 1983. "Literatura peruana: Totalidad Contradictoria". Revista de Crítica Literaria Latinoamericana 18: 37-50.

. 1993. "Ensayo sobre el sujeto y la representación en la literatura latinoamericana: Algunas hipótesis". Hispamérica 66: 3-15. 1988. "Los sistemas literarios como categorías históricas, Elementos para una discusión latinoamericana". Revista de Crítica Literaria Latinoamericana 29: 19-25. . Sobre literatura y crítica latinoamericanas. Lima: CELACP, 2013. 1996. "Una heterogeneidad no dialéctica: sujeto y discurso migrantes en el Perú moderno". Revista Iberoamericana 176-177: 837-844.

Coronil, Fernando. 1999. "Más allá del occidentalismo: hacia categorías históricas no imperiales". Casa de las Américas 206: 121-146.

De Grandis, Rita. 1997. "Incursiones en torno a hibridación: una propuesta para discusión. De la mediación lingüística de Bajtín a la mediación simbólica de García Canclini”. Revista de Crítica Literaria Latinoamericana 46: 37-51.

Franco, Jean. "Policía de frontera". 2001. Comp. Sarah de Mojica Culturas híbridas-No simultaneidad-Modernidad periférica. Mapas culturales para la América Latina.. Bogotá: CEJA. 47-52 .

García Canclini, Néstor. 1995. "Narrar la multiculturalidad”. Revista de Crítica Literaria Latinoamericana 42: 9-20.

2005. “Todos tienen cultura: ¿Quiénes pueden desarrollarla?” Conferencia para el Seminario sobre Cultura y Desarrollo, Banco Interamericano de Desarrollo, Washington. 2012. Culturas Hibridas. Buenos Aires: Paidós.

Gordon, Lewis. 2013. Decadencia disciplinaria. Pensamiento vivo en tiempos difíciles. Quito: Abya-Yala.

Hall, Stuart. 2013. Discurso y Poder. Huancayo: Melgraphic. . 2010. Sin Garantías. Trayectorias y problemáticas en estudios culturales. Lima: Envión Editores.

Laclau, Ernesto. 1993. "Discurso". Topos y Tropos: 7-18. 1996. Emancipación y diferencia. Buenos Aires: Ariel. 2005. La razón populista. Buenos Aires: FCE. 2014. Los fundamentos retóricos de la sociedad. Buenos Aires: FCE.

Laclau, Ernesto y Chantal Mouffe. 1987. Hegemonia y estrategia socialista. Madrid: Siglo XXI.

Lander, Edgardo. 2003. La colonialidad del saber: eurocentrismo y ciencias sociales. Buenos Aires: CLACSO.

Lechner, Norbert. 2002. Las Sombras del Mañana. La dimensión subjetiva de la política. Santiago: LOM.

Lienhard, Martin. 1999. "El campo de la literatura y el "Campus" Revista de Crítica Literaria Latinoamericana 50: 81-86. 
Moraña, Mabel. 1995. ““"Escribir en el aire. "Heterogeneidad” y Estudios culturales”. Revista Iberoamericana 170/171: 279-286.

Richard, Nelly. 1997. "Intersectando Latinoamérica con el latinoamericanismo: saberes académicos, práctica teórica y crítica cultural". Revista Hispanoamericana 180: 345-361.

Williams, Gareth. 2008. "El otro lado de lo popular: neoliberalismo y subalternidad en América Latina". Revista De/rotaR 1: 56-77.

Yúdice, George. 2002. "Contrapunteo estadounidense/latinoamericano de los estudios culturales". En Daniel Mato (coord.). Estudios y Otras Prácticas Intelectuales Latinoamericanas en Cultura y Poder. Caracas: Consejo Latinoamericano de Ciencias Sociales (CLACSO) y CEAP, FACES, Universidad Central de Venezuela. 339-352. 
